\title{
Sentinel-2 görüntüleri ve ICESat-2 ATL03 foton yükseklik verilerinin kombinasyonu ile batimetri haritası üretilebilirliğinin araştırılması
}

\author{
Mehmet Güven Koçak ${ }^{1}$ \\ ${ }^{1}$ Izmir Kâtip Çelebi Üniversitesi, Mühendislik Fakültesi, Harita Mühendisliği Bölümü, Çiğli, Izmir, Türkiye.
}

Öz: Batimetri haritaları akustik ve lazer gibi aktif algılayıcı sistemlerle yüksek doğruluklarla üretilebilmektedir. Yanal taramalı sonar, tek ve çok ışınlı iskandil gibi çeşitli akustik sistemlerin sığ sularda işletilmesi zor olup lazer sistemlerle ölçme yapılabilmesi de uygun optik geçirgenliğin varlı̆̆ına bağlıdır. İki sistemin uygulanmasında iş yükü, zamansal ve ekonomik maliyet dezavantajlarından da bahsedilmelidir. Öte yandan geniş bir sahay kapsayan ve erişilmesi güç konumlara ait multispektral görüntülerle $15 \mathrm{~m}$ derinliğe kadar sı̆̆ sularda batimetri haritası uygun maliyetle elde edilebilmektedir. Deneysel yaklaşım olarak bilinen bu yöntem uygulama yapılan sahadan toplanmış yeterli sayıda derinlik verisine ihtiyaç duyar. Bu çalışmada sahaya gitmeksizin, ICESat-2 ATL03 foton yükseklik verilerinden elde edilen dışsal derinlik ölçmeleri ile Sentinel-2 multispektral görüntüleri kombine edilerek bir çalışma alanının batimetri haritasının üretilmesi ve bu haritanın doğruluğunun test edilmesi amaçlanmıştır. Sentinel-2'nin klyı aerosol, mavi ve yeşil bantlarında ölçülen yansıma değerleri log-doğrusal ve log-oransal yaklaşımlar için ayrı ayrı olmak üzere çoklu doğrusal regresyonla modellenmiş ve bağıl derinlik haritası elde edilmiştir. Metrik olmayan bu harita eğitme verisi olarak seçilen, kırılma düzeltmesi getirilmiş ICESat-2 derinlik değerleri kullanılarak ölçeklendirilmiștir. Bu eğitme verisinden elde edilen çoklu doğrusal regresyon modeliyle batimetri haritası hesaplanmış, test alanının daha önce yanal taramalı sonar ile üretilmiş $60 \mathrm{~m}$ grid aralıklı batimetri haritasıyla karşılaştırılmıştır. Gerçekleştirilen karşılaş̧ırma testlerinde atmosferik düzeltme getirilmesinin sonuçları iyileştirmediği gözlenmiş, log-doğrusal yaklaşımla log-oransal yaklaşıma nazaran daha iyi doğruluk değerlerine ulaşılmıştır. Akustik olarak üretilen batimetri haritasından hesaplanan farklarla $\pm 1.6 \mathrm{~m}$ karesel ortalama hata değeri bulunmuş ve mutlak değerleri $5 \mathrm{~m}$ ve altında olan farkların sayısının toplam karşılaştırma noktalarının \%94'ünü oluşturduğu gözlenmiştir. Sentinel-2 ve ICESat-2 sinerjisiyle elde edilen batimetri haritası navigasyon için beklenen doğruluğu karşılamamaktadır. Ancak sahaya gitmeksizin, iki veri kümesi birleştirilerek optik geçirgenliğin haritalamaya izin verdiği sı $\breve{g}$ suların batimetri haritaları araştırma ve diğer uygulama çalışmaları için uygun maliyetle üretilebilir.

Anahtar Sözcükler: Batimetri, Sayısal yükseklik modeli, Sentinel-2, ICESat-2, Karesel ortalama hata, Çoklu doğrusal regresyon

\section{Investigation on the generation of bathymetric maps by combining Sentinel-2 imagery and ICESat-2 ATL03 photon height data}

\begin{abstract}
Bathymetry maps can be produced with high accuracy by using active acoustic and laser sensing systems. Various acoustic systems such as side-scan sonar, single and multi-beam echosounder are difficult to operate in shallow waters, and measurement with laser systems depends on the presence of appropriate optical transparency. Disadvantages such as workload, time, and economic costs should also be mentioned in the implementation of the two systems. On the other hand, bathymetry maps can be obtained in shallow waters up to a depth of $15 \mathrm{~m}$ at an affordable cost with multispectral images covering larger areas and remote/inaccessible locations. This method, known as the experimental approach, requires however sufficient field depth data. In this study, bathymetric map of a study area was generated by combining external depth measurements obtained from ICESat-2 ATL03 photon heights and Sentinel-2 multispectral images. This study aimed to test the accuracy of this bathymetric map against an existing map. Reflectance values measured in Sentinel-2's coastal aerosol, blue and green bands were modelled under multiple linear regression by using both log-linear and log-rational approaches, and as a result a relative depth map was obtained. The resultant non-metric map is scaled by refraction corrected ICESat-2 depth values building the model's training set. The bathymetry map was calculated with the multiple linear regression model obtained from this training set and compared with the existing side-scan sonar bathymetric map of the test area. The comparison tests revealed that the atmospheric correction did not improve the results, and better accuracy values were achieved with the log-linear approach compared to the log-rational approach. A root mean square error of $\pm 1.6 \mathrm{~m}$ was calculated from the comparisons to the acoustic bathymetry map. The number of differences having absolute values of $5 \mathrm{~m}$ and below constituted $94 \%$ of the total comparison points. Although the expected accuracy for navigation is not met, bathymetric maps of shallow areas with high optical transparency can still be obtained at a low cost by combining two independent satellite-based datasets for research and other applications.
\end{abstract}

Keywords: Bathymetry, Digital elevation model, Sentinel-2, ICESat-2, Root mean square error, Multiple linear regression 


\section{Giriş}

Karada etkisi; sıcaklıkların artması, yağışların düzensiz ve uç değerlere ulaşması, buzulların erimesi şeklinde görülen iklim değişikliği deniz faunasını ve florasını da etkilemektedir. Deniz çayır yoğunluğunun azalması, mercan resiflerinin beyazlaması, deniz seviyesinin yükselmesi bu değişimlere örnek olarak verilebilir (Pörtner, Roberts, Masson-Delmotte, \& Zhai, 2019). Deniz ekosisteminde ortaya çıkan bozulmaların azaltılması ve önlenmesi hatta uzun vadede ortadan kaldırılması ile bu ekosistemin sürdürülebilirliğinin sağlanması için uluslararası ilkeler benimsenerek harekete geçilmeye başlanmıştır. Uluslararası toplum tarafindan üzerinde anlaşmaya varılan sürdürülebilir kalkınma hedeflerinden 14'üncüsü deniz yaşam alanına odaklanmaktadır (United Nations, 2015). Avrupa Komisyonu tarafindan kabul edilen Starfish 2030 misyonu kapsamında belirlenen beş ana hedeften ilki olan "bilgi ve duygu boşluğu" altındaki alt hedeflerinden bir tanesi Avrupa deniz tabanının 2030 yılına kadar tamamının yüksek çözünürlükte haritalanmasıdır (Lamy vd., 2020). Deniz taban topoğrafyasının gerekliliğine dair dramatik bir deneyim Malezya Havayolları'na ait MH370 numaralı uçağın Kuala Lumpur'dan Pekin'e gitmekteyken 8 Mart 2014 tarihindeki uçuşu sırasında radardan kaybolarak Hint Okyanusu'na düşmesiyle yaşanmıştır. Yapılan arama kurtarma çalışmaları sırasında yaşananlar araştırmacılara Ay, Mars ve hatta Venüs yüzeyinin yeryüzünün deniz tabanından çok daha yüksek çözünürlüklerle haritalandırıldığını göstermiş̧tir (Tozer vd., 2019, URL-1).

Deniz taban topoğrafyasının sahada ölçmelerle elde edilmesinde deniz taşıtına monte edilen yanal taramalı sonar, tek ve çok ışınlı iskandil gibi modern yöntemler kullanılmaktadır. Bu sistemler ışın kaynağı olarak ses dalgalarını kullanan aktif sistemlerdir. Deniz taşıtı ile yerinde ölçüm planlı bir lojistik gerektirmekte olup zahmetlidir. Öte yandan akustik sistemlerle haritalama deniz taşıtının girebileceği yeterince derin kesimlerde gerçekleştirilebilir. Su yüzeyi ile teması zorunlu olan akustik algılayıcılara alternatif bir diğer yöntem ise optik lazer düzeneklerle gerçekleştirilen ölçmeleri kullanır. Su kütlesi üzerinde belirli bir yükseklikte hareket eden hava aracının taşıdığı sistem ölçme kaynağı olarak yeşil ve yakın kızılötesi dalga boylu lazer ışınlarını kullanır. Hava Lidar olarak isimlendirilen sistemle yeşil dalga boylu lazerin deniz tabanından, kızılötesi olanının da deniz yüzeyinden yansımaları ölçülerek derinlik verisi üretilir. Lazer ile ölçmeler akustik yöntemin aksine su bulanıklığının, lazerin geçirgenliğine izin verdiği daha çok kıyıya yakın sığ kesimlerinde gerçekleştirilebilir (Chust, Grande, Galparsoro, Uriarte, \& Borja, 2010). Her iki yöntemin ekonomik ve zamansal maliyeti yüksek olup yeryüzünün erişilmesi güç ve gerekli ölçme altyapısının bulunmadığı konumlar için uygulanmaları zordur (Gao, 2009; Kutser, Hedley, Giardino, Roelfsema \& Brando, 2020).

Yukarıda bahsedilen iki yönteme nazaran veri toplama süreci zahmetsiz, uygun maliyetli ve geniş alanların haritalanmasına olanak veren bir başka yöntem pasif algılayıcılarla elde edilen uydu görüntülerinden yararlanmaktadır. Uydu tabanlı batimetri, algılayıcıların gelişimine bağlı olarak multispektral ve hiperspektral görüntüler ile görüntü çiftlerini veri kaynağı olarak kullanır. Hiperspektral görüntülerle batimetri tayininde derinlik yanında suyun özellikleri ile taban yansıma değerlerinin birlikte kestirildiği fiziksel yaklaşım kullanılır (Lee, Carder, Mobley, Steward, \& Patch, 1998; Lee, Carder, Mobley, Steward, \& Patch, 1999; Chen, Yang, Xu, \& Huang, 2019). Uydu tabanlı hiperspektral sistemlerin mekânsal çözünürlükleri halihazırda $30 \mathrm{~m}$ civarında olup operasyonel bir karaktere henüz sahip değildirler (Vangi vd., 2021). Klasik fotogrametrik yöntemle sığ sularda batimetri belirlenebileceği yüksek çözünürlüklü WorldView-2 görüntü çifti örneğinde gösterilmiştir. Ancak fotogrametrik yöntemin başarısı görüntü eşleştirme için deniz tabanında uygun kontrast ile durgun su yüzeyinin varlığına bağlıdır (Hodúl, Bird, Knudby, \& Chénier, 2018).

Hiperspektral ve fotogrametrik yönteme nazaran uygulanması daha pratik olan multispektral görüntülerle batimetri belirleme deneysel yöntem olarak da bilinir ve uygulaması derinliğin, yansıma değerlerinin fonksiyonu olarak modellenmesi prensibine dayanır. Fonksiyonel model olarak iki yaklaşım ile uygulamada sıklıkla karşılaşılmakta; ilki yansıma değerlerinin 
logaritmalarını (Lyzenga, 1978; Lyzenga, Malinas, \& Tanis, 2006; Philpot, 1989) ikincisi ise bunların farklı bantlar için oranlarını kullanmaktadır (Stumpf, Holderied, \& Sinclair, 2003). Log-doğrusal ve log-oransal yöntem olarak da isimlendirilen her iki yaklaşım, modellenen bağımlı derinlik değişkeni için yeter sayıda saha örneklemesine ihtiyaç duyar. $\mathrm{Bu}$ da yöntemi yukarıda ele alınan diğer yöntem ve ölçme sistemlerine nazaran dezavantajlı hale getirmektedir. Ancak buzul kütlelerini takip etmek için tasarlanan ve 2018 Eylül ayında uzaya gönderilen ICESat-2 (The Ice, Cloud, and land Elevation Satellite-2) uydusuna ait verilerin 2019 yılı Mayıs ayı itibariyle kullanıcıların erişimine açılmasıyla bu dışsal veri sahaya gitmeksizin de sağlanabilmektedir. $532 \mathrm{~nm}$ dalga boylu lazer kullanan uydu sistemi ICESat-2 ile kıyıya yakın bulanık olmayan sularda derinlik değerleri gözlemlenebilmektedir. ICESat-2 ile ölçülen derinlik değerleri hava ve su kırılma katsayıları göz önüne alınarak hız düzeltmesi getirildikten sonra kullanılmalıdır (Parrish vd., 2019).

Sentinel-2 ve ICESat-2'nin birlikte kombinasyonu ile örnek olarak Güney Çin Denizi'ndeki Yongle mercan adaları ve Bahama'da (Ma vd., 2020), Bermuda, Girit ve Florida'daki üç test alanında (Thomas vd., 2021) batimetri haritaları üretilerek doğrulukları bağımsız verilerle test edilmiştir. İki sistemin entegrasyonu ile elde edilen batimetri haritalarının farklı coğrafi konumlarda, farklı özelliklere sahip alanlarda test edilmesi yöntemin operasyonel olarak uygulanıp uygulanamayacağını anlamaya imkân verecektir. Bu kapsamda bu çalışma, Sentinel-2+ICESat-2 kombinasyon yaklaşımının yanal taramalı sonar ile batimetri haritası mevcut ve tabanının belirli konumlarında Posidonia Oceanica deniz çayırı olan Gülbahçe Körfezi test alanında uygulanabilirliğini test etmeyi hedeflemektedir.

\section{Veri ve Yöntem}

Bu çalışma Sentinel-2 ve ICESat-2 uydu verilerini kombine ederek uydu tabanlı batimetri yöntemlerinden olan deneysel yaklaşımı kullanmış ve elde edilen batimetri haritasının testini gerçekleştirmiştir. Çalışma alanı olarak İzmir'in 45 km batısında, Karaburun Yarımadası'nın hemen sınırında yer alan Gülbahçe Körfezi alınmıştır. Körfez 58 km² alana sahip ve kuzeyde en derin yeri 30 m civarındadır, tabanı da deniz habitatı için önemli deniz çayırlarını barındırmaktadır (Şekil 1).
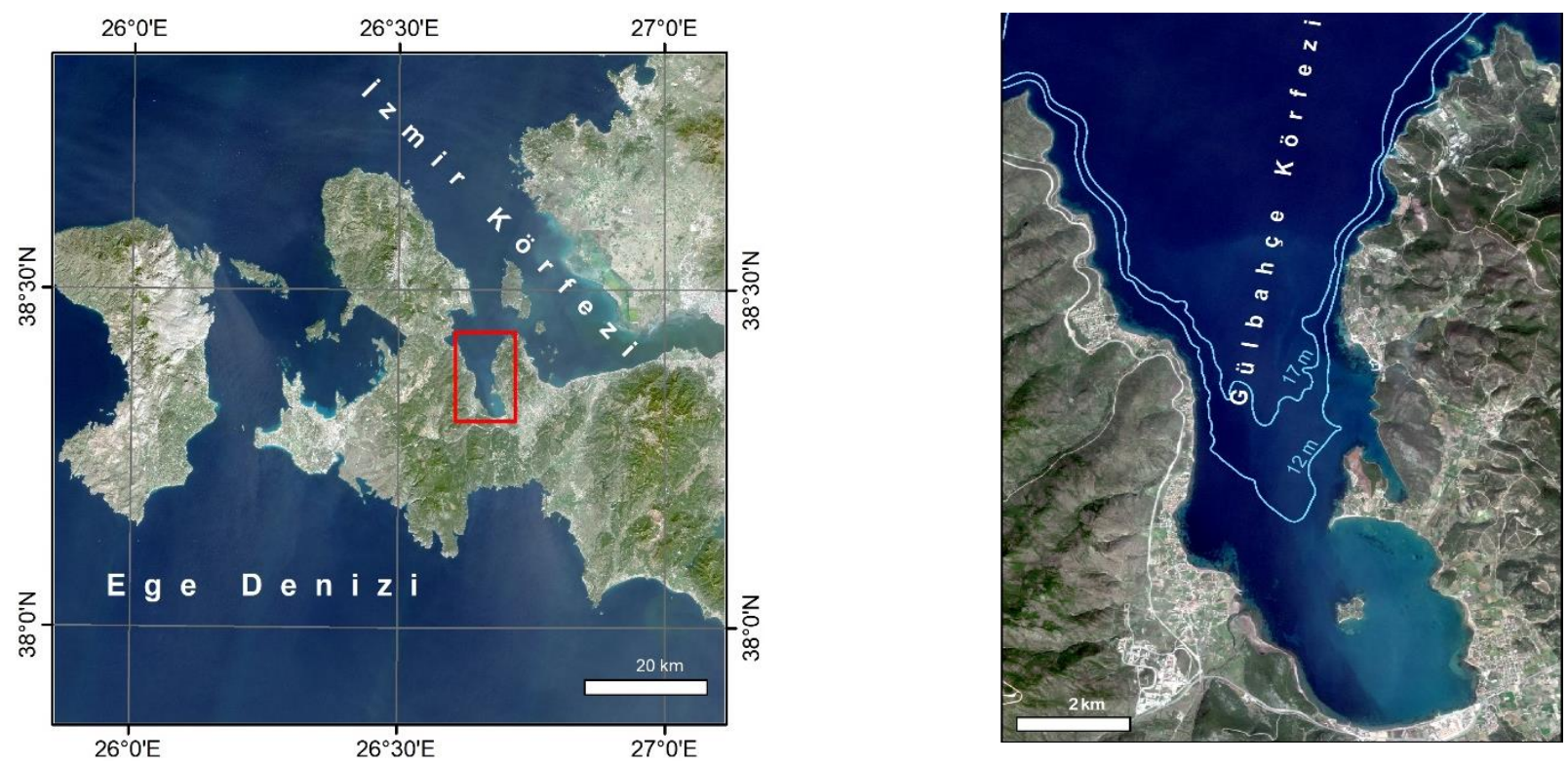

Şekil 1: 100 km x 100 km ebatı 4.3.2017 tarihli Sentinel-2A L2A görüntüsü (solda). Kırmızı ile gösterilen çerçeve çalışma alanı Gülbahçe Körfezi'ni göstermektedir (sağda)

\subsection{Sentinel-2 Uydu Görüntüsü}

Sentinel-2 Avrupa Komisyonu'nun Copernicus programı kapsamında işletilen, multispektral görüntüleme (Multispectral Imaging, MSI) kapasitesine sahip bir uydu sistemidir. Sistem 23 Haziran 2015 ve 7 Mart 2017 tarihlerinde firlatılan 2A ve 2B ikiz uydulardan oluşmakta ve her bir uydu yeryüzünün bir kesimini 10 gün aralıkla görüntüleyebilmektedir. Aynı 
yörüngede birbirlerinden $180^{\circ}$ faz açılı olarak dizilen $2 \mathrm{~A}$ ve $2 \mathrm{~B}$ ile görüntülemenin tekrarlama periyodu 5 güne inmektedir. İkiz uydular yerden 786 km yüksekte, kutupsal ve güneş eş zamanlı bir yörüngede hareket ederken yeryüzünü $290 \mathrm{~km}$ şerit genişliğinde tarayabilmektedirler. Uydulardaki MSI elektromanyetik spektrumun görünür, kızı̈ötesi ve kısa dalga kızı̈ötesi bölgelerinde olmak üzere toplam 13 bantta görüntüleme yapabilmektedir. Bunlardan dördü $10 \mathrm{~m}$, altısı $20 \mathrm{~m}$ ve geriye kalan üç adedi de 60 m yer örnekleme aralığına sahiptir (ESA, 2015).

Sentinel-2 görüntülerinin kullanıcılara erişimi Copernicus veri sunucusu (URL-2) üzerinden sağlanmaktadır. Veriler $100 \mathrm{~km}$ x 100 km'lik bloklar halinde ve UTM / WGS84 projeksiyon/datumunda verilmektedir. Sunucuda mevcut 2017-2020 yıllarını kapsayan dört yıllık veri bulutluluk, pus, güneş yansıması gibi bozucu etkilerin az olması ve körfezin kıyıya yakın kısımlarında deniz tabanının net olarak seçilebilmesi kriterleri göz önünde bulundurularak görsel olarak taranmış ve en uygun görüntü belirlenmiştir. Bu görüntü, çalışma alanı üzerinden saat 08:59'da (UTC) geçen 4 Mart 2017 tarihli seviye 1C (L1C) görüntüsüdür. Sentinel-2 L1C görüntüleri atmosfer tavanından yansıma değerlerini (Top Of Atmosphere, TOA) veren ürünlerdir. Çalışmada batimetrinin belirlenmesi için deniz tabanından en yüksek enerjili yansımayı veren ilk üç bandın kullanılması öngörülmüş̧ür. Bu bantlar kıyı aerosol (443 nm), mavi (490 nm) ve yeşil (560 nm) bantlarıdır ve yer örnekleme aralıkları sırasıyla 60, 10 ve 10 m şeklindedir. ESA'nın SNAP 6.0 yazılımı kullanılarak kıyı aerosol bant görüntüsü 10 m yer örnekleme aralığına sahip olacak şekilde yeniden örneklenmiştir. Çalışma kapsamında karşılaştırma yapmak üzere L1C görüntüsüne SNAP yazılımı içerisinde mevcut Sen2Cor v2.5.5 eklentisi kullanılarak atmosferik düzeltme de uygulanmıştır. Atmosferik düzeltme getirilerek oluşturulan yeni görüntü seviye 2A (L2A) görüntüsü olarak isimlendirilir ve atmosfer tabanından yani su yüzeyinden yansıma değerlerini vermektedir. L1C görüntüsünde güneş parıldama etkisi olup olmadığ test edilerek bu etkinin olmadığı da tespit edilmiştir (Kay, Hedley, \& Lavender, 2009).

\subsection{ICESat-2 Foton Yükseklik Verisi}

ICESat-2 uydusu NASA tarafindan 15 Eylül 2018 tarihinde buzul kütlelerin yüksekliklerinin değişimi ile bitki örtüsü yüksekliğinin belirlenmesi amaçlarıyla uzaya gönderilmiştir. Yerden $500 \mathrm{~km}$ yüksekte ve kutupsal bir yörüngede hareket eden ICESat-2 uydusu Advanced Topographic Laser Altimeter System (ATLAS) Lidar ölçme sistemini taşımaktadır. ATLAS üretmiş olduğu $532 \mathrm{~nm}$ dalga boylu üç lazer ışın çiftiyle yeryüzüne $10 \mathrm{kHz}$ frekansla foton kümesi gönderir ve bu şekilde uçuş doğrultusunda $\sim 70 \mathrm{~cm}$ 'lik bir örnekleme aralığında tarama elde edilir. Ortadaki referans izinden sol ve sağdaki izlere dik mesafe 3.3 km'dir. Her üç ana iz birbirinden uçuş doğrultusuna dik yönde $90 \mathrm{~m}$ uzaklıklı biri zayıf diğeri güçlü enerjiye sahip 1şınlarla taranır (Neumann vd. 2019; Ağca, 2020). Yeryüzüne gönderilen ve atmosferde iki kez seyahat ederek uyduya dönebilen fotonlar $80 \mathrm{~cm}$ çapındaki teleskop ile algılanarak çarptığı yer yüzeyi ile arasındaki mesafe ölçülmüss olur. Uydunun firlatılmasından sekiz ay sonra Mayıs 2019 tarihinde ICESat-2 verileri ücretsiz olarak kullanıma açılmıştır.

Sentinel-2 uydu görüntüsü yansıma değerleriyle elde edilen bağıl batimetri haritasını ölçeklemek üzere bu çalışmada ICESat2 ATL03 foton yükseklik verilerinden yararlanılmış, ilgili verilere OpenAltimetry platformu üzerinden ulaşılmıştır (Khalsa vd., 2020; Neumann vd., 2021). Çalışma alanı üzerinden geçen 312, 754 ve 1280 numaralı yörüngeler detaylı olarak incelenerek deniz tabanından yansıma elde edilebilen veri setleri tespit edilmiştir. Deniz tabanından yansıma suyun bulanıklığına ve izin konumuna bağlı olarak değişmektedir (Parrish vd., 2019). Yapılan öncül hesaplamalar yalnızca 1280 numaralı yörüngeden alınan 21 Haziran 2019 tarihli yükseklik verilerinin incelenen diğer profillere nazaran daha yüksek doğruluklar ürettiğini ortaya koymuştur. Bu nedenle uydunun ilgili tarihte saat 01:46'daki (UTC) geçişinde yüksek enerjili gt1l isimli ışın ile elde edilen profil değerlendirmeye alınmıştır (Şekil 2). ATL03 yükseklikleri elipsoidal yükseklikler olarak verilmekte ve bu yüksekliklere katı yer gel-git, okyanus yüklemesi gibi çeşitli jeofizik düzeltmeler getirilmektedir (Neumann vd., 2021). Sentinel-2 ve ICESat-2 verilerinin alındığı tarihler arasında ICESat-2’ye ait uygun profil seçme zorunluluğu nedeniyle yaklaşık 27 aylık bir zaman farkı oluşmuş, bu süre içinde deniz tabanında herhangi bir değişim olmadığı 
varsayılmıştır.
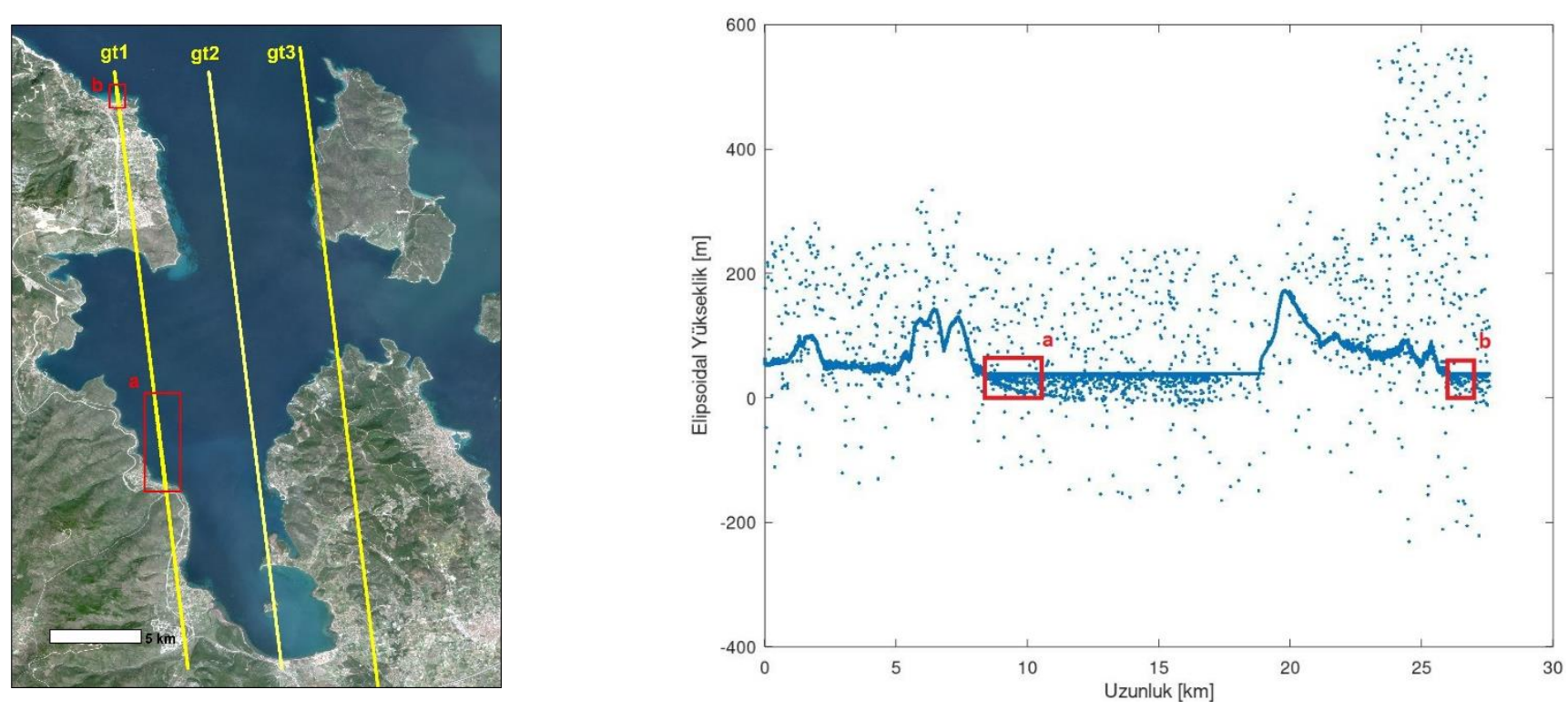

Şekil 2: (Sol) 21 Haziran 2019 tarihinde 01:46’da (UTC) çalışma alanı üzerinden geçen 1280 numaralı yükselen uydu yörüngesinden yapılan taramaların yer izleri. (Sağ) Analizde kullanılan gt1l izine ait yükseklik profili görülmektedir.

Şekil 2'de (Sağ) a ve b ile gösterilen, kıyıya yakın konumlarda deniz tabanından foton dönüşü olduğundan derinlik verisine ulaşılması mümkün olmuştur. Ancak elde edilen ham derinlik değerleri, deniz suyunun kırılma indisinin havanın kırılma indisinden büyük olması nedeniyle gerçek derinlik değerlerinden daha büyük olarak elde edilmektedir. Snell yasası kırılma indisi (n) ve ortamda ışı̆̆ın yayılma hızı (v) değerleriyle

$\frac{n_{\text {hava }}}{n_{\text {su }}}=\frac{v_{\text {su }}}{v_{\text {hava }}}$

şeklinde yazılabilir. Burada kuru havanın ve deniz suyunun kırılma indisleri $532 \mathrm{~nm}$ dalga boylu 1şık için sırasıyla 1.0003 ve 1.34150 alınarak (Mobley, 2010) hesaplama yapılırsa 1şı̆̆ın su ve havadaki yayılım hızları arasındaki bağıntıdan ölçülen ve gerçek derinlikler arasındaki ilişki

$h_{\text {gerçek }} \approx 0.7457 h_{\text {ICESat-2 }}$

şeklinde çıkarılabilir. Buna göre gerçek derinlik değeri, ICESat-2 ile ölçülen derinlik değerinin yaklaş1k olarak \%75'ine karşılık gelmektedir. Şekil 2'de (Sağ) b ile çerçevelenen konumdaki ICESat-2 profili ile (2) eşitliği ile hesaplanan profil Şekil 3'te karşılaştırmalı olarak gösterilmektedir. 


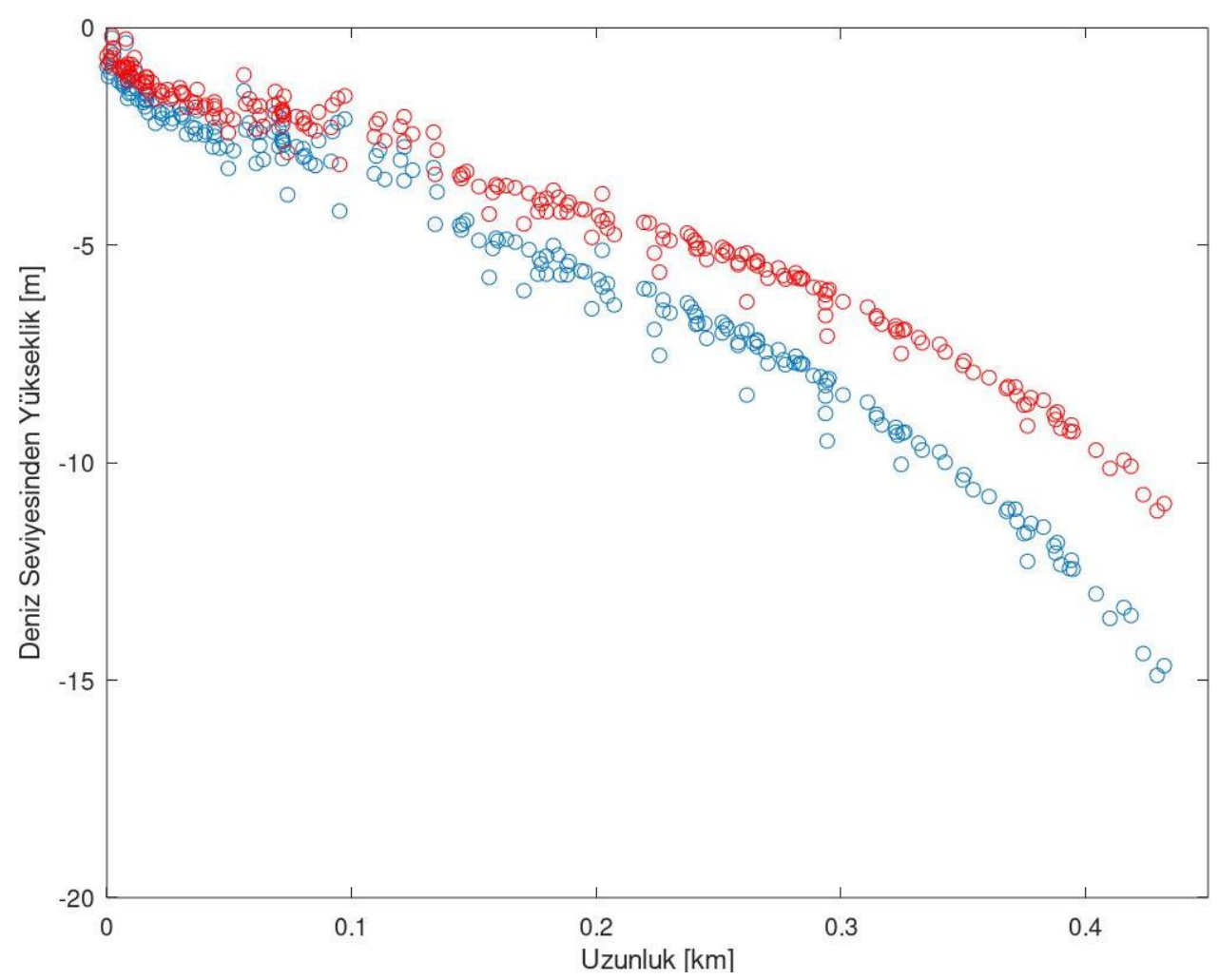

Şekil 3: Şekil 2'de b ile gösterilen konumdaki gürültüden arındırılmış ICESat-2 profili, Şekil kırılma indisi düzeltmesi getirilmemiş (mavi) ve getirilmiş (kırmızı) deniz seviyesinden yükseklik değerlerini göstermektedir.

\section{3 Çoklu Doğrusal Regresyon Modeli}

ICESat-2'nin körfez üzerinden geçişi sırasında deniz tabanından elde edilen derinliklerin aynı konumlardaki Sentinel-2 yansıma değerleriyle modellenmesinde iki farklı yaklaşım uygulanmıştır. Her iki yaklaşım da çoklu doğrusal regresyon parametrik modelini kullanır ve model fonksiyonu her bir bant için su yüzeyinde ölçülen yansıma değerinin deniz tabanına doğru derinliğin üstel bir fonksiyonu olacak şekilde azaldığı varsayılarak oluşturulur. İlk yöntemde model katsayıları yansıma değerlerinin logaritması ile

$z=\alpha_{0}+\sum_{i=1}^{M} \alpha_{i} \log \left(r_{i}-r_{i}^{\infty}\right), \mathrm{M}=$ Bant sayısı

şeklinde yazılabilir (Lyzenga, Malinas \& Tanis, 2006). Log-doğrusal yaklaşımda model katsayılarının hesabında bir banttaki yansıma değerinden aynı bandın su kütlesinin sonsuz derin bir konumundaki yansıma değerinin çıkarıldığına dikkat edilmelidir. Pratikte sonsuz derin bir konum yerine görüntü üzerinde en derin konumdaki ilgili banttaki ortalama yansıma değeri kullanılabilir. $\alpha$ değerleri kestirilecek $\mathrm{M}+1$ sayıda model parametrelerini göstermektedir.

İkinci yöntem (3) eşitliğinde verilen yansıma değerlerinin logaritmaları yerine bu değerlerin oranlarını katsayı olarak hesaplar:

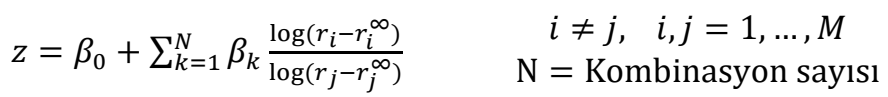

Eşitlikte geçen $\beta_{k}$ değerleri parametre tahmini ile bulunacak $\mathrm{N}+1$ sayıda parametreyi ifade etmektedir. Burada kombinasyon sayısı ile bant sayısı arasında $N=M \times(M-1)$ ilişkisi vardır. 
(3) ve (4) eşitliklerinin sol tarafindaki değerler ilgili noktalara ait ICESat-2'den elde edilen derinliklerdir. Bölüm 2.2'de de gösterildiği gibi ICESat-2'den elde edilen değerlere kırılma düzeltmesi getirilerek değerlendirme yapılmıştır. Log-doğrusal ve log-oran temelli modellere hangi bantların ve kombinasyonların dahil edilmesinin anlamlı olduğuna ise Akaike Bilgi Kriteri (ABK) (Akaike, 1973) çerçevesinde karar verilmiştir.

\section{Bulgular}

Multispekral görüntülerle deneysel yaklaşım kullanarak elde edilen batimetri haritası bağıl bir haritadır ve ölçeklenebilmesi için dışsal veriye ihtiyaç duyar. Bu çalışmada dışsal veri olarak kullanılan ICESat-2 derinlikleri (3) ve (4) eşitliklerinde verilen model parametrelerinin kestirilebilmesi için model katsayılarıyla beraber eğitme kümesini oluştururlar. Log-oransal ve log-doğrusal model parametreleri atmosferik düzeltme getirilmemiş atmosfer tavanı yansımalarını içeren L1C ve düzetme getirilmiş atmosfer tabanına ait L2A Sentinel-2 görüntülerinin her ikisi için de kestirilmiştir. Çoklu doğrusal regresyon modeli Sentinel-2'nin yalnızca kıyı aerosol, mavi ve yeşil bantları ile gerçekleştirilmiştir. Bu üç banda ilaveten kırmızı bandın da katkısının olup olmadığı test edilmiş, bu bandın dahil edilmesiyle ABK değeri az bir oranda düşmüş ancak doğruluk değeri anlamlı olarak değişmediğinden üç bantla hesaplama yapılması benimsenmiştir.

Eğitme kümesi ile yapılan kestirimlerle elde edilen dört çözüm Şekil 4'te sunulmaktadır. Şekildeki yatay eksenler ölçülen ICESat-2 derinlik değerlerini düşey eksenler ise model parametreleri ile hesaplanan derinlik değerlerini göstermektedir. Örnekleme noktalarında model uyumu \%93 ve üzeri değerler olarak karşımıza çıkmaktadır. Yansıma değerleri için L1C veya L2A görüntüsünün altllk olarak alınması log-doğrusal ve log-oransal yaklaşımların her ikisi için de anlamlı farklar üretmemiştir. Ancak model katsayılarının hesabında log-doğrusal yaklaşım kullanılmasıyla log-oransala nazaran daha iyi doğruluk değerleri elde edilmiştir. L1C görüntüsü için log-doğrusal yaklaşım ile $\pm 0.44 \mathrm{~m}$ karesel ortalama hata kestirilirken log-oransalda bu değer \pm 0.63 m'ye yükselmektedir. Çoklu doğrusal regresyon modeliyle hesaplanan derinlikler gerçek ICESat-2 derinliklerinden daha küçük olarak ortaya çıkmaktadır. Ayrıca eğitme verisi sonuçlarına göre model derinlikleri ICESat-2 derinlik değerlerinden log-doğrusal yaklaşımda $\sim 0.1 \mathrm{~m}$ diğer yöntemde ise $\sim 0.2 \mathrm{~m}$ ötelenmiş daha derin değerler olarak elde edilmektedir.

Eğitme aşamasında elde edilen regresyon model parametreleri ile görüntünün her bir pikselinin kıyı aerosol, mavi ve yeşil bant yansıma değerleriyle o piksel konumu için derinlik değerleri hesaplanmıştır. Atmosferik düzeltme getirilmiş L2A görüntüsüyle sonuçlarda anlamlı bir iyileşme olmadığından yalnızca L1C görüntüsü derinlik hesabında kullanılmıştır. Elde edilen batimetri haritası karşılaştırma öncesinde $5 \times 5$ ebatlı medyan filtrelemesine tabii tutulmuştur. Daha sonra yanal taramalı sonar ile üretilmiş $60 \mathrm{~m}$ grid aralıklı batimetri haritasının (bkz. Şekil 5 sol sütun) tüm grid orta noktaları Sentinel-2+ICESat2 kombinasyonu ile elde edilen raster derinlik haritasına aktarılmış ve bu nokta konumlarına karşılık gelen derinlik değerleri doğrusal enterpolasyonla bulunmuştur. Sonar derinlik değerlerinden model derinlik değerleri çıkarılarak farklar hesaplanmıştır. Elde edilen farklar körfezde mevcut Posidonia Oceanica deniz çayırı konumlarında negatif işaretli oldukça büyük değerler olarak bulunduğundan Şekil 5 sağ sütunda gösterilen deniz çayırı alanları değerlendirme dışı bırakılmıştır. Log-doğrusal ve log-oransal yaklaşımlar için ilgili farkların $1 \mathrm{~m}$ aralıklı frekans yüzdeleri ile kümülatif yüzde değerleri Şekil 6'da görülmektedir. Log-doğrusal çözümde sahadaki tüm karşılaştırma noktalarının \%69.6'sında mutlak fark değeri 2 m'nin altında bulunmuştur. Mutlak değerce $5 \mathrm{~m}$ ve altında fark gösteren konumlar karşılaştırma noktalarının \%94.2'sini oluşturmaktadırlar. Log-oransal çözümde bu say1 \%85.5 olarak gözlemlenmiştir. Log-oransal çözümle elde edilen farkların mutlak değerlerinin $5 \mathrm{~m}$ üzerinde ortaya çıktığı nokta sayısı tüm noktaların \%5.8’i iken bu oran log-doğrusal çözümde \%14.5'dir. Log-oransal çözümde bu noktaların daha fazla oluşu, modelin oran ifadesi içermesi nedeniyle ortaya çıkan sayısal bir etkinin sonucudur. 

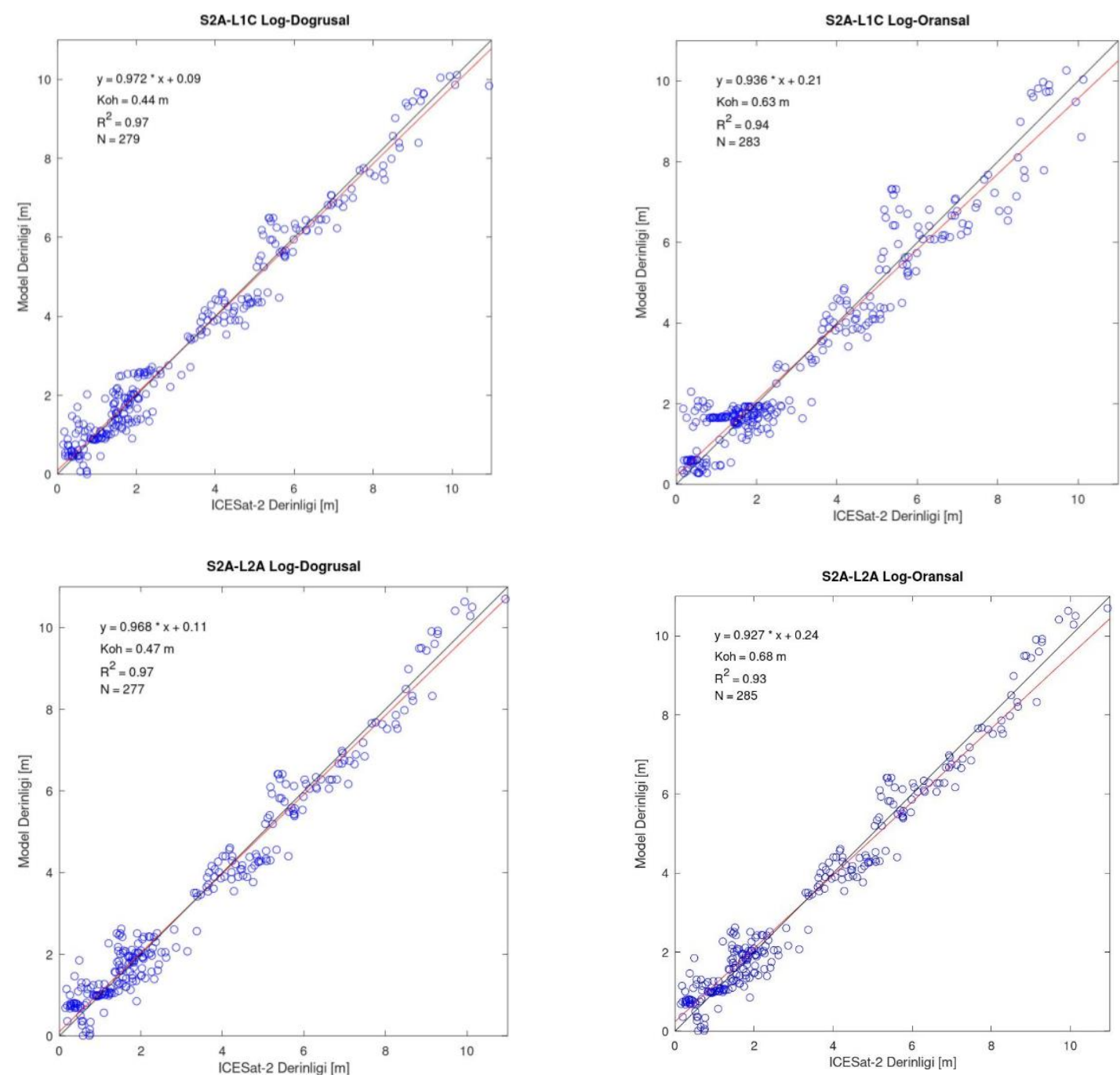

Şekil 4: Sentinel-2A L1C (üstte) ve L2A (altta) görüntüleri kullanarak oluşturulan çoklu doğrusal regresyon modelinin log-doğrusal ve log-oransal yaklaşımlarılyla hesaplanan model derinlik değerlerinin ICESat-2 derinlik değerlerine bağı̆ değişimi.
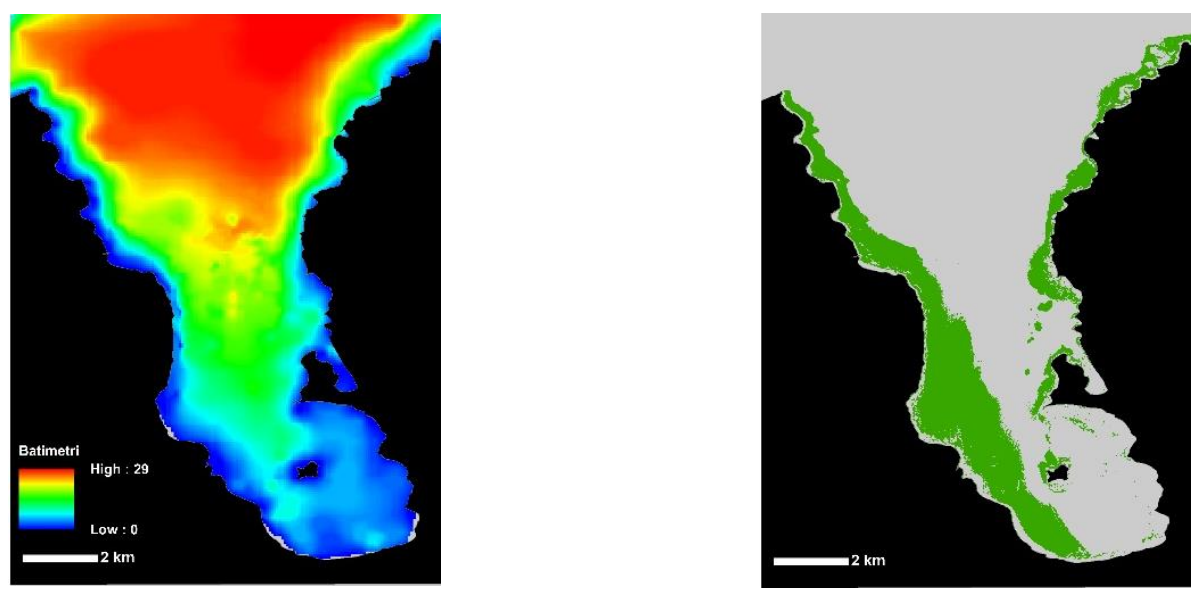

Şekil 5. (Sol) Yanal taramalı sonar ile üretilen $60 \mathrm{~m}$ grid aralıklı batimetri haritası. (Sağ) Alandaki Posidonia oceanica deniz çayırlarının dağııımını gösterir harita (Yücel - Gier vd., 2019). 

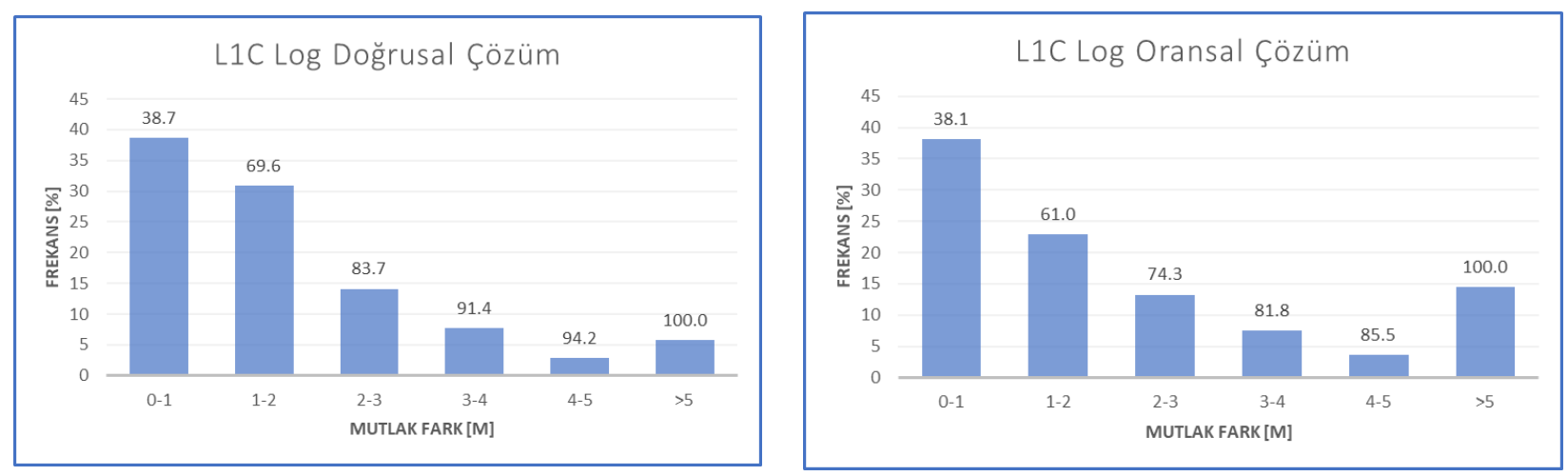

Şekil 6: Yanal taramalı sonar batimetri haritası ile Sentinel-2+ICESat-2 kombinasyonu ile üretilen haritanın karşılaştırılması sonucunda bulunan farkların mutlak değerlerinin $1 \mathrm{~m}$ aralık içinde kalan nokta sayılarının tüm nokta sayılarına oranlarını gösterir yüzde değerleri ile kümülatif yüzdeler.

Eğitme verisi ile bulunan model parametrelerinin genelleme doğruluğu Şekil 7'deki grafikte sunulmaktadır. Grafiğin yatay ekseni hatasız olarak alınan akustik verilerle üretilmiş batimetri değerlerini, düşey eksen ise modelle hesaplanan derinlik değerlerini göstermektedir. Karşılaştırmada derinlik sınırı olarak 12 m alındığına dikkat edilmelidir. Log-doğrusal yaklaşım log-oransala kıyasla biraz daha iyi sonuçlar üretmiştir. ICESat-2 konumlarında elde edilen farklarla bulunan ve sonucu Şekil 4'te sunulan model, karesel ortalama hata \pm 0.44 m ve model uyumu \% 97 elde edilmişken modelin tüm çalışma alanına uygulanmasıyla bu değerler sırasıyla $\pm 1.56 \mathrm{~m}$ ve \% 74 olarak bulunmuştur. ICESat-2 profilinin yalnızca taş ve kum taban malzemesinden olan bir bölgede elde edilmesi nedeniyle ideal, yüksek doğruluk gözlenmiştir. Öte yandan karşılaştırma yapılan konumlarda çamur varlığı da mevcuttur. Bir başka önemli husus uygun veri bulunamaması nedeniyle yalnızca bir ICESat-2 derinlik profilinden yararlanılabilmiş olması durumudur. Bu profil tek başına alanın tümü göz önüne alındığında heterojen bir dağılım gösteren taban malzemesi ve su kalitesi çeşitliliğini temsil etmemekte bunun sonucunda da daha yüksek karesel ortalama hata değeri bulunmaktadır (Vinayaraj, Raghavan, \& Masumoto, 2016).
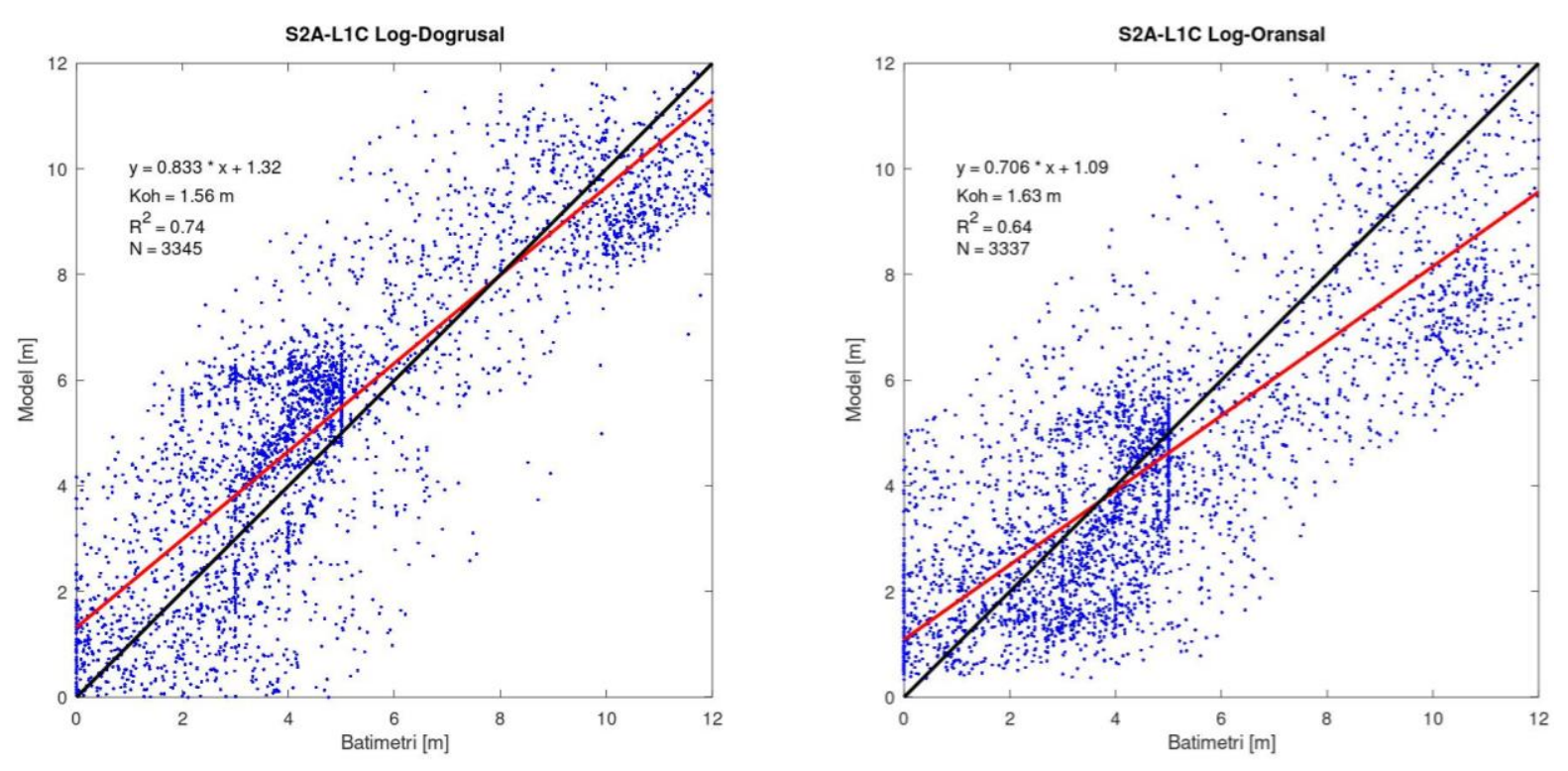

Şekil 7: Yanal taramalı sonar batimetri derinlikleri ile Sentinel-2A+ICESat-2 kombinasyonu ile üretilen model derinliklerinin karşılaştırılması

\section{Sonuçlar}

Bu çalışmada Sentinel-2 raster görüntüsü ile ICESat-2 ATL03 foton yükseklik verileri kullanılarak İzmir Gülbahçe Körfezi'nin batimetri haritası üretilmiş ve bu haritanın doğruluğu test edilmiştir. Uydu görüntülerinden yararlanarak deniz tabanını ilgilendiren çalışmalarda ve batimetri haritası üretiminde, güneşten gelen 1şınların su kütleleri tarafından soğurulmaları daha az olan elektromanyetik spektrumun mavi ve yeşil bölgesindeki bantların kullanılması gerekmektedir. 
Batimetri haritası üretiminde Sentinel-2'nin kıyı aerosol, mavi ve yeşil bantlarındaki yansıma değerleri log-doğrusal ve logoransal yaklaşımda kullanılarak çoklu doğrusal regresyon modeli uygulanmıştır.

Deniz çayırı olan konumlardaki ICESat-2 verileri eğitme verisine dahil edilmiş ancak bu konumlardaki yansıma değerlerinin düşük olmaları ve derinlikle değişen kontrast vermemeleri nedeniyle derinlik değerleri olması gerekenden daha büyük olarak hesaplanmıştır. $\mathrm{Bu}$ nedenle deniz çayırı olan konumlar hem eğitme hem de model genellemesiyle bulunan batimetri haritasının gerçek batimetri haritasıyla karşılaştırmasında değerlendirme dışında bırakılmıştır.

Uydu görüntüleriyle gerek deniz tabanı haritalanması gerekse de batimetri haritası üretilmesi çalışmanın yapılacağı sulardaki optik geçirgenlikle doğrudan ilişkilidir. Gülbahçe Körfezi’nde daha önce yapılan bir çalışmada, bu çalışmada kullanılan aynı tarihli Sentinel-2 görüntüsü kullanılarak optik geçirgenliğin ölçütlerinden olan Secchi Disk Derinliği (SDD) hesaplanmıştır (Yücel-Gier, Koçak, Akçalı, İlhan, \& Duman, 2020). Buna göre çalışma sahasındaki ortalama SDD değeri 10-12 m civarında olup bu değer Sentinel-2 ve ICESat-2 kombinasyonu ile üretilen batimetri haritasının etkin olarak hesaplanabileceği limiti de belirlemektedir (Caballero, Stumpf \& Meredith, 2019; Parrish vd., 2019).

Sentinel-2 ve ICESat-2'nin birlikte sinerjisiyle elde edilen batimetri haritaları farklı konumlarda yine farklı araştırmacılar tarafından üretilmiş ve test edilmiştir. Ma vd. (2020) çalışmalarında maksimum derinliğin \%10’una kadar bir doğruluk gözlemlemiş̧lerdir. Üç farklı konumda gerçekleştirilen doğrulama çalışmalarında Thomas vd. (2021) ise bu oranı \%15 olarak vermektedirler. Thomas vd. (2021)'nin çalışma alanlarından biri Girit adasının kuzeybatısında yer almakta ve iklim ve su kalitesi itibariyle Gülbahçe Körfezi’ne benzer özellikler göstermektedir. Çalışmalarında optik geçirgenliği daha yüksek olmasına rağmen $22 \mathrm{~m}$ derinliğe kadar farklı yöntemlerle batimetrik derinlik elde edebildiklerini belirtmektedirler. Uyguladıkları üç farklı yöntemden en iyi sonucu veren yöntemle $\pm 2.19 \mathrm{~m}$ karesel ortalama hata değeri ile $0.89 \mathrm{R}^{2}$ uyum değeri bulmuşlardır. Bu değer maksimum derinliğin \%10’una tekabül etmektedir. Bu çalışmada 12 m maksimum derinlikle $\pm 1.56 \mathrm{~m}$ karesel ortalama hata bulunmuş bu da maksimum derinliğin \%13’ünü oluşturmaktadır. Aradaki fark Girit çalışma alanındaki optik geçirgenliğin, Gülbahçe Körfezi'ndekinden daha iyi olmasıyla açıklanabilir.

Sentinel-2 ve ICESat-2 verilerinin kombinasyonu ile oluşturulan batimetri haritasının doğruluğunun navigasyon için gerekli Uluslararası Hidrografi Örgütü (International Hydrographic Organization, IHO) standartlarını sağlamadığı belirlenmiştir (IHO, 2020). Bu sadece Sentinel-2 ve ICESat-2 tabanlı batimetri haritaları için değil aynı zamanda Landsat 8 uydu görüntüleriyle elde edilen batimetri haritaları için de tespit edilmiş bir durumdur (Kılıç Güngör, 2019; Açar, 2021). Ancak erişilemeyen uzak konumlardaki sığ sularda batimetri haritaları navigasyon dışındaki diğer kullanım amaçları için Sentinel2 ve ICESat-2 kombinasyonu ile üretilebilir. Sentinel-2 görüntüsü kullanmanın avantajı beş günlük zamansal çözünürlüğe sahip olması nedeniyle batimetri haritası üretilecek alanın en uygun atmosfer ve su koşuluna sahip görüntülerini elde etme şansının yüksek olmasıdır. Burada en önemli problem aynı yörüngeden geçiş zaman aralığının 91 gün olması nedeniyle ICESat-2 uydusundan uygun derinlik profillerinin temininde ortaya çıkabilecektir.

\section{Teşekkür}

Dokuz Eylül Üniversitesi Deniz Bilimleri ve Teknolojisi Enstitüsü’nden Prof. Dr. Muhammet Duman'a Gülbahçe Körfezi’ne ait batimetri haritasını, Avrupa Uzay Ajansının Sentinel Veri Merkezi’ne Sentinel-2 uydu görüntülerini ve OpenAltimetry platformuna ICESat-2 ATL03 verilerini teminleri için içten teşekkür ederim. 


\section{Çıkar Çatışması Beyanı}

Yazar, bu çalışmada bilinen ilgili herhangi bir finansal veya finansal olmayan çıkar çatışması olmadığını beyan eder.

\section{Kaynaklar}

Açar, K. (2021). Hidrografik Mesaha Planlama Aşamasında Uydu Tabanlı Batimetrik Veri Kullanımının Araştırllması (Yüksek lisans tezi). İstanbul Teknik Üniversitesi, Fen Bilimleri Enstitüsü, İstanbul, Türkiye

Ağca, M. (2020). PALS, ICESat/GLAS ve ICESat-2 Lazer Sistemleri ve Kullanım Alanları. Geomatik, 5(1), 27-35.

Akaike, H. (1973). Information Theory and an Extension of the Maximum Likelihood Principle. In B. N. Petrov, \& F. Csaki (Eds.), Proceedings of the 2nd International Symposium on Information Theory, 267-281. Budapest

Caballero, I., Stumpf, R. P., \& Meredith, A. (2019). Preliminary assessment of turbidity and chlorophyll impact on bathymetry derived from Sentinel-2A and Sentinel-3A satellites in South Florida. Remote Sensing, 11(6), 645.

Chen, B., Yang, Y., Xu, D., \& Huang, E. (2019). A dual band algorithm for shallow water depth retrieval from high spatial resolution imagery with no ground truth. ISPRS Journal of Photogrammetry and Remote Sensing, 151, 1-13.

Chust, G., Grande, M., Galparsoro, I., Uriarte, A., \& Borja, Á. (2010). Capabilities of the bathymetric Hawk Eye LiDAR for coastal habitat mapping: a case study within a Basque estuary. Estuarine, Coastal and Shelf Science, 89(3), 200-213.

ESA. (2015). Sentinel -2 user Handbook (2nd ed.). European Space Agency Standard Document, 64.

Gao, J. (2009). Bathymetric mapping by means of remote sensing: methods, accuracy and limitations. Progress in Physical Geography, 33(1), 103-116.

Hodúl, M., Bird, S., Knudby, A., \& Chénier, R. (2018). Satellite derived photogrammetric bathymetry. ISPRS Journal of Photogrammetry and Remote Sensing, 142, 268-277.

International Hydrographic Organization (IHO) (2020). IHO Standards for Hydrographic Surveys (6th Edition). IHO Publication S-44. Monaco.

Kay, S., Hedley, J. D., \& Lavender, S. (2009). Sun glint correction of high and low spatial resolution images of aquatic scenes: a review of methods for visible and near-infrared wavelengths. Remote Sensing, 1(4), 697-730.

Khalsa, S. J. S., Borsa, A., Nandigam, V., Phan, M., Lin, K., Crosby, C., Fricker H., Baru, C., Lopez, L., \& Lopez, L. (2020). OpenAltimetry-rapid analysis and visualization of Spaceborne altimeter data. Earth Science Informatics, 1-10.

Kılıç Güngör, B. (2019). Uydu Görüntüleri Yardımı ile Batimetrik Harita Üretimi: Kozlu Balıkçı Barınağı Örneği (Yüksek lisans tezi) Zonguldak Bülent Ecevit Üniversitesi, Fen Bilimleri Enstitüsü, Zonguldak, Türkiye.

Kutser, T., Hedley, J., Giardino, C., Roelfsema, C., \& Brando, V. E. (2020). Remote sensing of shallow waters-a 50 year retrospective and future directions. Remote Sensing of Environment, 240, 111619.

Lamy, P., Citores, A., Deidun, A., Evans, L., Galgani, F., Heffernan, P., Karageorgis A., Kauppi L., Manakovski D., Meissner G., Moldoveanu V., Ramm K., Pedicchio, M. C., Pitta e Cunha, T., Slat, B., \& Pons, G. (2020). Mission Starfish 2030: Restore our ocean and waters. Report of the Mission Board Healthy Oceans, Seas, Coastal and Inland Waters.

Lee, Z., Carder, K. L., Mobley, C. D., Steward, R. G., \& Patch, J. S. (1998). Hyperspectral remote sensing for shallow waters. I. A semianalytical model. Applied Optics, 37(27), 6329-6338.

Lee, Z., Carder, K. L., Mobley, C. D., Steward, R. G., \& Patch, J. S. (1999). Hyperspectral remote sensing for shallow waters: 2. Deriving bottom depths and water properties by optimization. Applied Optics, 38(18), 3831-3843.

Lyzenga, D. R. (1978). Passive remote sensing techniques for mapping water depth and bottom features. Applied Optics, 17(3), $379-383$.

Lyzenga, D. R., Malinas, N. P., \& Tanis, F. J. (2006). Multispectral bathymetry using a simple physically based algorithm. IEEE Transactions on Geoscience and Remote Sensing, 44(8), 2251-2259.

Ma, Y., Xu, N., Liu, Z., Yang, B., Yang, F., Wang, X. H., \& Li, S. (2020). Satellite-derived bathymetry using the ICESat-2 lidar and Sentinel-2 imagery datasets. Remote Sensing of Environment, 250, 112047.

Mobley, C. D. (2010). Optical properties of water. Handbook of optics, 4, 1.3-1.53. 
Neumann, T. A., Martino, A. J., Markus, T., Bae, S., Bock, M. R., Brenner, A. C., Brunt, K.M., Cavanaugh, J., Fernandes, S.T., Hancock D.W., Harbeck, K., Lee, J., Kurtz N.T., Luers P,J., Luthcke S.B., Magruder L., Pennington P.A., Ramos-Izquierdo, L., Rebold T., Skoog J., \& Thomas, T. C. (2019). The Ice, Cloud, and Land Elevation Satellite-2 Mission: A global geolocated photon product derived from the advanced topographic laser altimeter system. Remote Sensing of Environment, 233, 111325.

Neumann, T. A., Brenner, A., Hancock, D., Robbins, J., Saba, J., Harbeck, K., Gibbons, A., Lee, J., Luthcke, S. B., Rebold, T. vd. (2021). ATLAS/ICESat-2 L2A Global Geolocated Photon Data, Version 4 (ATL03), Boulder, Colorado USA, NASA National Snow and Ice Data Center Distributed Active Archive Center, https://doi.org/10.5067/ATLAS/ATL03.004, (Erişim Tarihi: 5 Mayıs 2021).

Parrish, C. E., Magruder, L. A., Neuenschwander, A. L., Forfinski-Sarkozi, N., Alonzo, M., \& Jasinski, M. (2019). Validation of ICESat2 ATLAS bathymetry and analysis of ATLAS's bathymetric mapping performance. Remote Sensing, 11(14), 1634.

Philpot, W. D. (1989). Bathymetric mapping with passive multispectral imagery. Applied Optics, 28(8), 1569-1578.

Pörtner, H. O., Roberts, D. C., Masson-Delmotte, V., \& Zhai, P. (Eds.). (2019). The Ocean and Cryosphere in a Changing Climate: A Special Report by the Intergovernmental Panel on Climate Change. Intergovernmental Panel on Climate Change.

Stumpf, R. P., Holderied, K., \& Sinclair, M. (2003). Determination of water depth with high-resolution satellite imagery over variable bottom types. Limnology and Oceanography, 48, 547-556.

Thomas, N., Pertiwi, A. P., Traganos, D., Lagomasino, D., Poursanidis, D., Moreno, S., \& Fatoyinbo, L. (2021). Space-Borne CloudNative Satellite-Derived Bathymetry (SDB) Models Using ICESat-2 And Sentinel-2. Geophysical Research Letters, 48(6).

Tozer, B, Sandwell, D. T., Smith, W. H. F., Olson, C., Beale, J. R., \& Wessel, P. (2019). Global bathymetry and topography at 15 arc sec: SRTM15+. Earth and Space Science, 6, 1847.

United Nations (2015). Transforming our world: The 2030 agenda for sustainable development. United Nations, Department of Economic and Social Affairs. New York.

Vangi, E., D’Amico, G., Francini, S., Giannetti, F., Lasserre, B., Marchetti, M., \& Chirici, G. (2021). The New Hyperspectral Satellite PRISMA: Imagery for Forest Types Discrimination. Sensors, 21(4), 1182.

Vinayaraj, P., Raghavan, V., \& Masumoto, S. (2016). Satellite-derived bathymetry using adaptive geographically weighted regression model. Marine Geodesy, 39(6), 458-478.

Yücel-Gier, G., Koçak, G., Akçalı, B., İlhan, T., \& Duman, M. (2019). Mapping of Posidonia oceanica (L.) Delile in the bay of Gülbahçe. Proceedings of the Mediterranean Symposium on Marine Vegetation. Antalya, Turkey, 98-102.

Yücel-Gier, G., Koçak, G., Akçalı, B., İlhan, T., \& Duman, M. (2020). Evaluation of Posidonia oceanica Map Generated by Sentinel-2 Image: Gülbahçe Bay Test Site. Turkish Journal of Fisheries and Aquatic Sciences, 20(7), 571-581.

URL-1: https://www.oceansofbiodiversity.auckland.ac.nz/2019/03/23/the-ocean-floor-is-less-well-mapped-than-the-surface-of-otherplanets/ (Erişim Tarihi: 27 Mart 2021).

URL-2: Copernicus Sentinel-2 Veri Sunucusu, https://scihub.copernicus.eu/ (Erişim Tarihi: 15 Mart 2021). 